\title{
EXPERIMENTAL STUDY OF THE INTERFACIAL WAVES PRODUCED IN UPWARD VERTICAL ANNULAR FLOWS WHEN VARYING THE LIQUID-PHASE SURFACE TENSION
}

\author{
YAGO RIVERA, JOSÉ-LUIS MUÑOZ-COBO, CÉSAR BERNA, \\ JOSÉ-LUIS CUADROS \& ALBERTO ESCRIVÁ \\ Instituto de Ingeniería Energética, Universitat Politècnica de València, Spain
}

\begin{abstract}
A flow pattern, which appears in many industrial applications, is annular two-phase flow. Its main characteristic is that the main portion of the liquid mass is located at the walls of the tube forming an annulus, while the gas phase flows through the annulus core dragging small liquid drops. These drops are largely produced by the interactions of the gas-phase flowing through the gas core with the peaks of the disturbance waves, which are produced in the liquid/gas interface. This paper describes a set of experiments performed at the Vertical Annular Film Flow facility, in the annular flow regime, with upward liquid and gas flows, at different flow conditions varying the liquid surface tension by adding small amounts of 1-butanol to the water. The main property of 1-butanol is that small amounts of this substance significantly change the surface tension while the viscosity remains practically unchanged. The set of experiments were carried out inside a vertical tube $44 \mathrm{~mm}$ inner diameter, and $4.5 \mathrm{~m}$ high, the annular flow was created by means of a porous material with known porosity coefficient. The experimental conditions range from 2000 to $3500 \mathrm{l} / \mathrm{min}$ for the gas volumetric flow rate, and from 4 to $10 \mathrm{l} / \mathrm{min}$ for the liquid volumetric flow rate at atmospheric conditions. Several experiments have been carried out on 1-butanol varying the water surface tension from $72 \times 10^{-3} \mathrm{Nm}^{-1}$, to $45 \times 10^{-3} \mathrm{Nm}^{-1}$, at intermediate surface tensions. To measure the height of the disturbance waves and the thickness of the film we use a conductance probe - the electrical signal collected in the receiver sensor depends on the thickness of the liquid film layer. Correlations for the amplitude of the disturbance waves, the film base thickness and other physical magnitudes have been obtained with a good value for the coefficient of determination and the root mean square error.
\end{abstract}

Keywords: annular flow, interfacial disturbance waves, film thickness, ripple waves.

\section{INTRODUCTION}

Annular flow is found in many industrial applications and it is one of the fundamental heat transfer modes in industrial processes involving phase change, as for instance boiling water reactors (BWR), heat exchangers, refrigeration, some solar plants among others [1], [2]. In power plants with vertical tubes heated by nuclear energy as in BWR or other energy sources as coal, gas or solar, the two-phase mixture flows upward. Beyond a given distance from the bottom of the heated tubes the two-phase mixture becomes annular, this means that the liquid phase flows upward forming an annulus in contact with the tube walls. This ring or annulus has a gaseous core, which also flows in the upward direction and that exerts a shear stress on the liquid/gas interface. Because the gas velocity is normally bigger than the liquid velocity this shear stress can drag small drops from the crest of the waves formed at the interface. Two different types of waves coexist at the interface, the first ones that have bigger amplitudes and longer lifetimes are known as disturbance waves (DW). These waves are coherent in the streamwise direction and move according to Azzopardi et al. and Belt et al. with approximately constant velocity. The second ones, which have small amplitudes and that are not coherent over large distances are known as ripples waves (RW) [3]-[7]. 
Many studies have been carried out on annular flow (Berna et al. [3], [4], Alekseenko et al. [5], [8], Belt et al. [6] and Azzopardi [7]) most of them focused on the characterization of the gas-liquid interfacial waves behaviour. These interfacial waves play a determinant role in the droplet entrainment processes, increasing also the pressure drop along the pipe and affecting significantly to the mass, momentum and heat transfer processes, because of these interfacial structures promote an extra drag on the gas flow like roughness [4], [6], [8]. This extra roughness can be accounted for considering the frontal area of these DWs. Due to its high relevance, in all these transfer processes, it is necessary an adequate characterization of the interfacial waves specially the DWs. From previous studies it has been found, for instance, the increase of the liquid film thickness with the liquid flow rate, its decrease with the gas flow rate, the increase of the wave velocity and frequency with the flow rate, for both, gas and liquid phases, the weak dependency of DWs characteristics with the pipe diameter, and so forth [9].

The research of the physical phenomena hidden behind annular flow are pursued throughout this work, having as a major objective, to produce correlations for the major interfacial variables and to compare it against other widely used expressions. As another important goal of the present work, we investigate the influence of the surface tension on the DWs behaviour, variable which has not been so widely studied. In previous studies it has been found that the Kapitza number plays a fundamental role in the development of the interfacial waves [10], this nondimensional number depends fundamentally of the surface tension and the viscosity. Because the height of the disturbance waves is significantly affected by the surface tension value, then it is important to address experimental studies in this direction. This paper presents an experimental study of changing the surface tension of the water by adding small amount of 1-butanol, which has the property that small amount of 1-butanol, changes the surface tension of the water without practically affecting the viscosity. Because an increase in the amount of 1-butanol added to the water produce a diminish in the surface tension with a smaller change in the viscosity then we can study how the amplitude of the disturbance waves is affected by the temperature by simulating the increases in the fluid temperature by the increments in the concentration of 1-butanol. The paper has been organized as follows: Section 2 is devoted to describing the experimental facility and the experimental method used. Section 3 is devoted to describing the experiments performed and the main experimental results. Finally, Section 4 is devoted to present the main conclusions of the paper.

\section{THE EXPERIMENTAL VERTICAL ANNULAR FILM FLOW FACILITY AND THE EXPERIMENTAL METHODS}

\subsection{Description of the VAFF experimental facility}

A schematic view of the VAFF facility (Vertical Annular Flow Facility) is displayed in Fig. 1. The VAFF facility is an air-water loop with different sensors placed along its length, in order to measure the water film thickness and to know if the flow is fully developed. The facility main dimensions for the test section are almost $5 \mathrm{~m}$ of useful vertical length with an inner pipe diameter of $44 \mathrm{~mm}$. Its major components are the air production circuit, the water production system, the injector/mixer system, the test section and the air-water separator system. The main physical variables are measured with different sensor types, which are strategically distributed along the facility for the purpose pursued. 


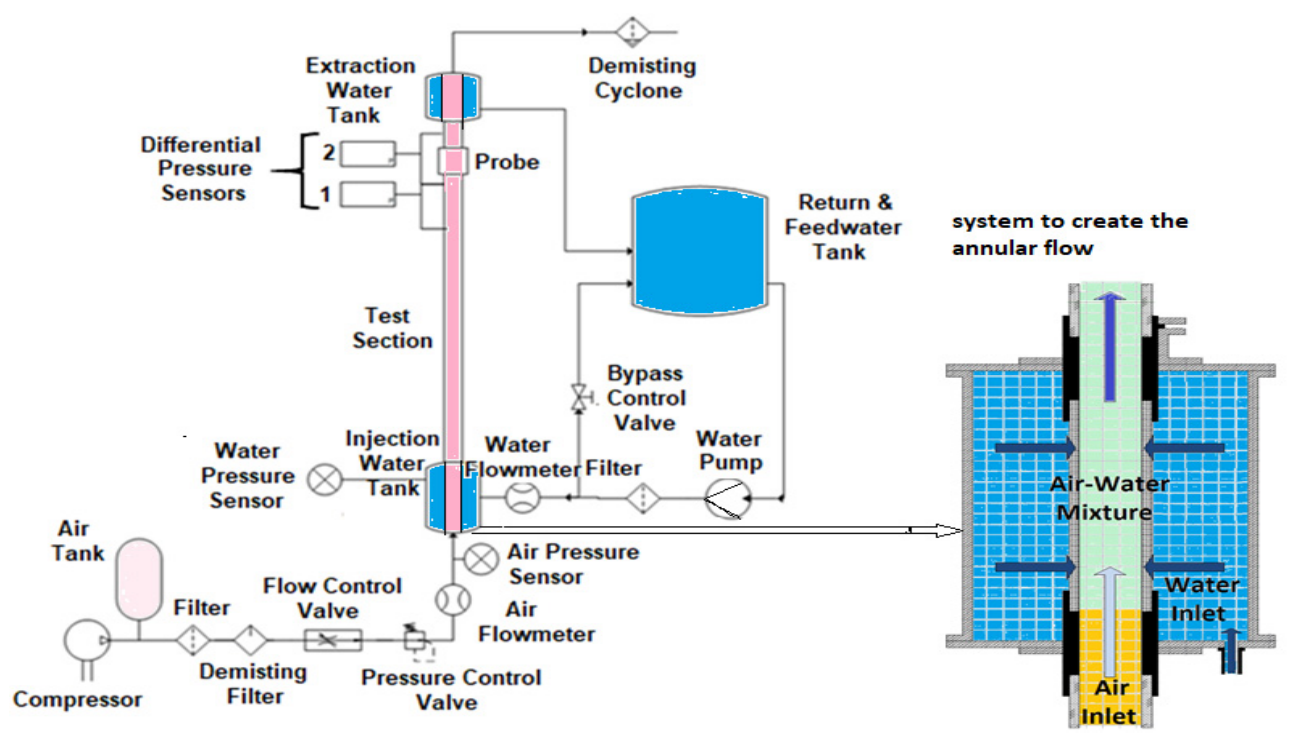

Figure 1: Schematic layout of the VAFF facility, with a detailed description of the water injector system, which creates the annular flow.

The operation and characteristics of the facility can be summarized as follows:

- Air is injected into the system through a compressor, whose maximums working pressure and volumetric flow rate are 8 bars and 3750 l/min respectively.

- Water is injected through a water pump, whose maximum discharge pressure is 4.2 bars.

- A specific designed pressurized water injector system is used to create a thin annulus liquid film just before the lower part of the test section. The water injector's operating principle is based on the pressure difference between both sides of the sintered stainlesssteel tube with a given porosity value.

- The water injection system is a cylindrical tank displayed also in Fig. 1, with a hollowed central part and a sintered stainless-steel tube in it. The outer part of the cylinder is pressurized, while through its inner part circulates the air stream at almost atmospheric pressure. Due to the porosity of the sintered material the water current can pass through it, being the water volumetric flow rate function of the pressure difference between the inner and outer sides of the sintered stainless-steel material.

- The two-phase flow crosses through the test section, in which most of the experimental measurements are taken.

- The outer liquid annulus is removed through the extraction water tank in the upper part of the test section. The operating principle of the extraction tank is the same one as in the water injection system.

- The water is returned to a storage tank, from which the water is sucked by the recirculation pump and driven to the injector system once again, starting a new water cycle.

- The two-phase mixture, composed by the gas phase and entrained droplets, is separated through a centrifugal demisting cyclone. 
- The air is vented to the atmosphere through the final section of the centrifugal demisting cyclone.

- Fresh air is injected back into the experimental facility by the compressor and the air cycle starts once again.

The test section consists of a vertical methacrylate tube of approximately 4 meters high and an inner diameter of $44 \mathrm{~mm}$. All the major experimental measurements are taken along this test section, absolute and differential pressure sensors, thermocouples and, the most important one, the conductance probe.

\subsection{Instrumentation and data acquisition}

\subsubsection{Facility instrumentation}

The VAFF facility is equipped with two differential pressure sensors located in the upper part of the test section, as displayed in Fig. 1, in order to know if the two-phase flow is fully developed at the measuring point for the experimental conditions of the experiment. These relative pressure measurements are made with SMC PSE550 low differential pressure transducers. These sensors have a pressure range measurement between 0 to $2 \mathrm{kPa}$, with accuracy equal or higher than $\pm 1.0 \%$ at full scale (F.S.) and a linearity error equal or less than $\pm 0.5 \%$ F.S.

The local measurements of pressure are made with Burkert 8314 relative pressure transducers (difference in pressure between the inner part of the facility and the surrounding atmosphere). These sensors have a pressure range measurement between 0 and 1 bar, with a sum of linearity, hysteresis and repeatability errors less than $\pm 0.3 \%$ F.S. and error adjustment accuracy zero point and full scale less than $\pm 0.3 \%$ F.S.

Temperature measurements were performed with Type $\mathrm{T}$ thermocouples (copperconstantan), which are suitable in the range -200 to $350^{\circ} \mathrm{C}$. Their error, for measurements above $0^{\circ} \mathrm{C}$, is the greater value between $1.0^{\circ} \mathrm{C}$ and $0.75 \%$ of the measured temperature.

Water volumetric flow rate measurements are made with a Kroni Optiflux $4300 \mathrm{C}$ Series electromagnetic flowmeter. Its volumetric flow rate measurement interval ranges from 0 to $20 \mathrm{l} / \mathrm{min}$ and has an accuracy higher than $\pm 0.3 \%$ of span.

Measurements of the high-speed gas volumetric flow rate are made with a SMC PF2A706 H magnetic flowmeter. Its volumetric flow rate measurement range covers from 300 to $6000 \mathrm{l} / \mathrm{min}$, the flowmeter has a linearity of \pm 1.5 of full scale (F.S.) or less and a repeatability of \pm 1.0 F.S. or less.

\subsubsection{Conductance probe}

To estimate the characteristics of the interfacial waves we use a conductance probe. The conductance probe used in these measurements is described in reference [11]. The physical basis of the conductance sensors is the dependence of the water conductivity on the film thickness value [12]. The conductance probe design consists of three electrodes mounted flush with the wall and aligned in the same flow direction of the liquid film and the gas flow. The central electrode is connected to the ground. The transmitter electrode is excited, with a $300 \mathrm{KHz}$ and $4 \mathrm{Vpp}$ sinusoidal signal. The receiver electrode is responsible for collecting the electric current that the water film conduces. The total amount of current collected by the receiver is proportional to the liquid film thickness between both electrodes i.e. the transmitter and the receiver. This dependency is caused by the existing correlation between the liquid film thickness and the electric field lines, because of higher film thickness leads to higher number of electric field lines, which can be collected by the receiver. Consequently, the electric signal collected by the receiver changes when an interfacial wave crosses the 
sensor region, and this change allows the determination of the liquid film thickness variations with time. The receiver signal is rectified and amplified by an electronic circuit explained below and then registered in the data acquisition system. At the same time, this signal gives us the wave's form when it is plotted versus time.

To insert the sensors of the conductance probe in the test section we have used a PolyPropylene (PPR) pipe section denoted as port. The geometrical characteristics of the port are an inner diameter of $44 \mathrm{~mm}$, equal to that of the test section, and a total length of $170 \mathrm{~mm}$. Slots have been created at both ends of the port, so that the measuring tube fits perfectly and does not cause any disturbance in the liquid film entering or leaving the port. The electrodes have been placed in the central part of the port.

\subsubsection{Electronic circuit and data acquisition system}

The internal operations carried out by the sensor electronic circuit consist on the following steps: The sinusoidal signal produced by the generator is amplified before sending it to the excitation electrode. Next, the receiver electrode captures the signal, which has been transmitted through the liquid layer. This last signal is amplified again and transformed in DC current by a rectifier. Then, the data acquisition system acquires this DC signal, whose value is related to the liquid film thickness existing between both electrodes. Then, the variations with time in the value of this DC signal will indicate the passage of waves present in the liquid film.

During the test runs all the instrumentation devices, described in the previous sections, are monitoring in real time all the major experimental conditions, which include air and water volumetric flow rates, temperatures and pressures, in addition to the recording of the experimental data along the test section, i.e. conductance probe signal and pressure testsection values. The data acquisition system has been programmed in LabView. This system distinguishes between two types of measurements: The conductance probe measurements, which suffer fast variation with time and need high sample rates, and the rest of measurements as temperature and pressure. The acquisition system for the conductance probe records $10^{5}$ samples per second (S/s) (National Instruments PCI 6255 with 80 analogic channels and a maximum rate of $1.25 \mathrm{MS} / \mathrm{s}$ ). For the rest of experimental data, which suffers smaller variations with time, the acquisition system records 100 samples per second (National Instruments cDAQ-9174 chassis compact-DAQ with a module NI 9207 of 16 analogic channels and a maximum rate of $500 \mathrm{~S} / \mathrm{s}$ ).

\subsection{Calibration}

The final step performed before placing the conductance probe in the experimental facility is the calibration of the conductance sensor. The objective is to relate the voltage signal with the water film thickness. For the measurement performed adding 1-butanol to the water, the sensor calibration must be repeated for each 1-butanol concentration, because the water conductivity changes with the 1-butanol concentration. Proceeding is this way it is possible to relate the information contained in the signals (V) with the amplitude of the waves produced in the fluid interface $(\mathrm{mm})$. We remind that the conductance sensor consists of 3 electrodes with $2 \mathrm{~mm}$ of inner diameter, spaced $1.5 \mathrm{~mm}$ between them, and aligned in the direction of flow and flush in the inner wall of the pipe.

The calibration process was carried out with a calibration device, displayed in Fig. 2. This device consists of three major components: one optical precision table; a precision positioning system mounted on this table with an error of $0.002 \mathrm{~mm}$; and several cylinders with known diameters and made with a dielectric material. By setting the dielectric cylinder 
at the desired position, in the inner part of the conductance probe port, by means of the precision positioning system, we can know the fluid thickness between the dielectric and the probe electrodes. Measuring the voltage in the probe electrode, we can find the relationship between the signal voltage and the fluid thickness.

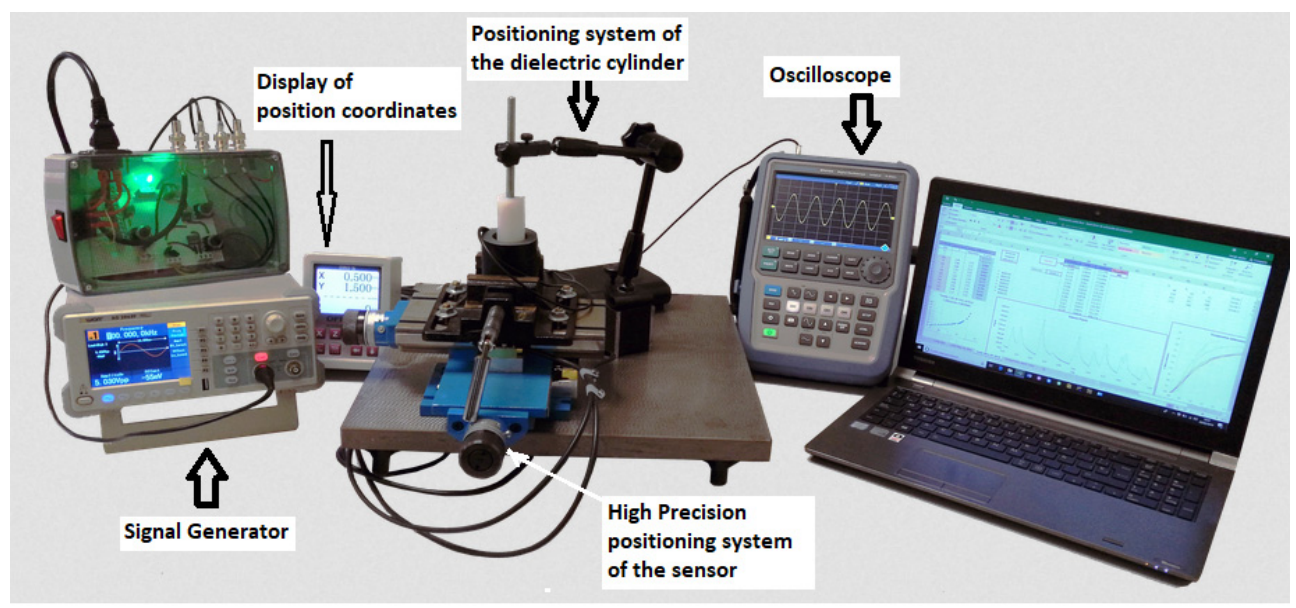

Figure 2: High precision calibration device.

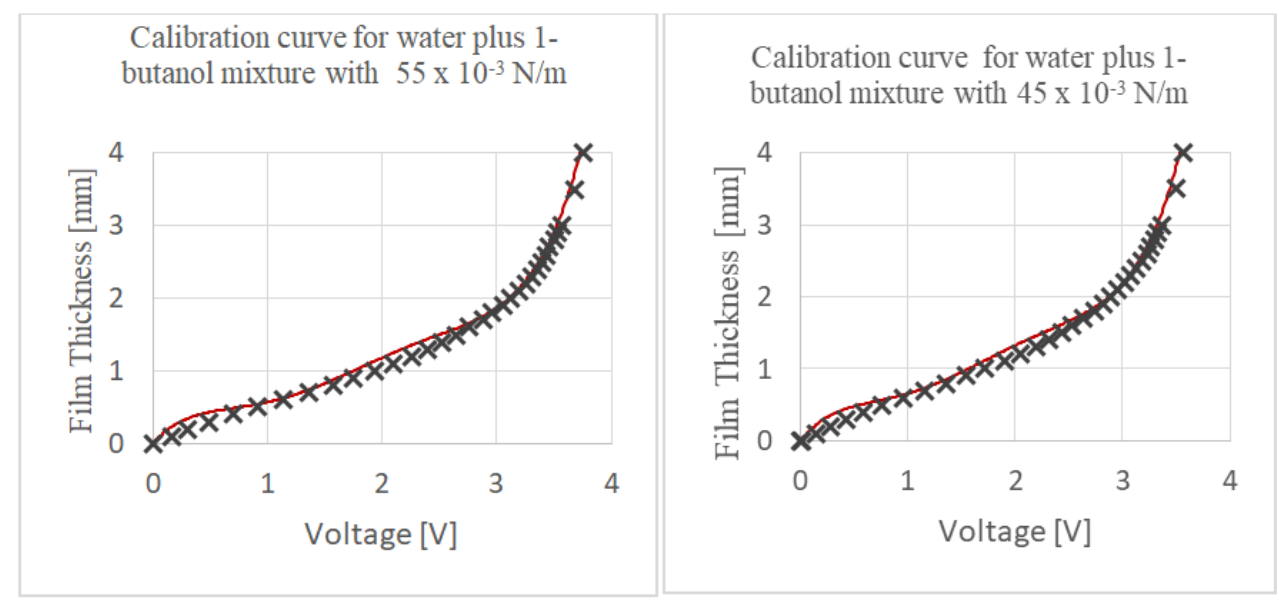

Figure 3: Calibration curve for two of the experiments performed adding 1-butanol to the water, the crosses denote the experimental points.

A total number of 33 calibration measurements were made with the calibration device for each one of the three 1-isobutanol concentrations values, which are denoted by their surface tensions at $25^{\circ} \mathrm{C}, 68.510^{-3} \mathrm{~N} / \mathrm{m}, 5510^{-3} \mathrm{~N} / \mathrm{m}$ and $4510^{-3} \mathrm{~N} / \mathrm{m}$. Two of the calibration curves obtained for the cases of $5510^{-3} \mathrm{~N} / \mathrm{m}$ and $4510^{-3} \mathrm{~N} / \mathrm{m}$ are displayed at Fig. 3. We notice that the calibration curves displayed have similar shapes although their values are not the same. 
The calibration curve fitted to the 1-butanol calibration experiments was a polynomial of fifth degree given by eqn (1), with coefficients denoted by the symbols $x_{0}$ to $x_{5}$, while for the pure water was the curve given by eqn (2):

$$
\begin{gathered}
\delta(m m)=x_{0}+x_{1} V+x_{2} V^{2}+x_{3} V^{3}+x_{4} V^{4}+x_{5} V^{5} \\
\delta(m m)=a+b_{1} V^{b_{2}}+c_{1} V^{c_{2}}+d_{1} V^{d_{2}}+e_{1} V^{e_{2}}
\end{gathered}
$$

The coefficients of the curves for each one of the 1-butanol concentrations are displayed in Table 1. The uncertainty in the calibration using eqn (1) was estimated using the methods explained in Chapter 7 of Bevington and Robinson [13]. The estimated uncertainty for the 1-butanol case with $\sigma=68.510^{-3} \mathrm{~N} / \mathrm{m}$, was $0.28 \mathrm{~mm}$.

Table 1: Coefficients of the calibration curves for the 1-butanol plus water experiments.

\begin{tabular}{|c|c|c|c|c|c|c|}
\hline$\sigma(N / m)$ & $\mathrm{x}_{5}$ & $\mathrm{x}_{4}$ & $\mathrm{x}_{3}$ & $\mathrm{x}_{2}$ & $\mathrm{x}_{1}$ & $\mathrm{x}_{0}$ \\
\hline $68.510^{-3}$ & 0.038 & -0.384 & 1.388 & -2.089 & 1.535 & 0. \\
\hline $5510^{-3}$ & 0.088 & -0.733 & 2.203 & -2.779 & 1.789 & 0. \\
\hline $4510^{-3}$ & 0.105 & -0.833 & 2.403 & -2.946 & 1.925 & 0. \\
\hline \multicolumn{7}{|c|}{ Pure water $\left(\sigma=72 \times 10^{-3}\right)$} \\
\hline$a$ & $b_{1}$ & $b_{2}$ & $c_{1}$ & $c_{2}$ & $d$ & $d_{2}$ \\
\hline 0.046 & -5.416 & 3.481 & -3.032 & 0.958 & 6.242 & 4.381 \\
\hline$e_{1}$ & $e_{2}$ & & & & & \\
\hline 5.176 & 0.953 & & & & & \\
\hline
\end{tabular}

\section{EXPERIMENTAL MEASUREMENTS AND RESULTS}

The test matrix consisted of four experimental data series, each data series was performed with a constant concentration of 1-butanol, which produced a given surface tension. Each data series consisted of several runs with different boundary conditions i.e. different volumetric flow rates of air and water respectively, which are displayed at Table 2 . The number of data series was 4 , one for water with a surface tension of $72 \times 10^{-3} \mathrm{~N} / \mathrm{m}$, at $25^{\circ} \mathrm{C}$ and three additional ones obtained adding small amount of 1-butanol, which yields surface tensions of $68.510^{-3} \mathrm{~N} / \mathrm{m}, 55.10^{-3} \mathrm{~N} / \mathrm{m}$ and $45.10^{-3} \mathrm{~N} / \mathrm{m}$. For each solution of water-1butanol 49 experimental runs were made, which were obtained by combination of seven gas and seven liquid volumetric flow rates. The seven liquid flow rates covered from 4 to $10 \mathrm{l} / \mathrm{min}$, with increments of $1 \mathrm{l} / \mathrm{min}$ from run to run. While the seven air volumetric flow rates changed between $2000 \mathrm{l} / \mathrm{min}$ to $3500 \mathrm{l} / \mathrm{min}$ (i.e., $0.0333-0.0583 \mathrm{~m}^{3} / \mathrm{s}$ ), increasing 250 $1 / \mathrm{min}$ between different runs. This procedure was repeated for the rest of 3 water-1-butanol mixtures. The major objective of changing the water surface tension is to study the strongly effects suffered by the interfacial wave's behaviour, in response to variation in the surface tension. Because diminishing the water surface tension value is quite like the effect of the temperature increase. During all the experimental measurements the pressure in the upper part of the facility was kept at atmospheric conditions, the water and air temperatures were kept approximately constant at about 30 and $25^{\circ} \mathrm{C}$ respectively.

The most important variables of the experiment were monitored in real time during the 49 test runs of each one of the four data series. Then main variables that were monitored and stored during the sixty seconds of each experimental run were: air and water volumetric flow rates, temperatures and pressures, in addition to the conductance probe voltage signal, which was converted in mm using the calibration curves displayed in Section 2.3. 
Table 2: Boundary conditions of the 49 experimental runs performed for each surface tension, the units of $Q_{g}$ and $Q_{l}$ are $1 / \mathrm{min}$.

\begin{tabular}{|c|c|c|c|c|c|c|}
\hline \multicolumn{7}{|c|}{ Boundary conditions used for the surface tension $\sigma=72 \times 10^{-3} \mathrm{~N} / \mathrm{m}$} \\
\hline$Q_{g} \times Q_{l}$ & \multicolumn{7}{|c|}{$Q_{g}(\mathrm{l} / \mathrm{min}) \times Q_{l}(\mathrm{l} / \mathrm{min})$} & $Q_{g} \times Q_{l}$ \\
\hline $2000 \times 4$ & $2250 \times 4$ & $2500 \times 4$ & $2750 \times 4$ & $3000 \times 4$ & $3250 \times 4$ & $3500 \times 4$ \\
$2000 \times 5$ & $2250 \times 5$ & $2500 \times 5$ & $2750 \times 5$ & $3000 \times 5$ & $3250 \times 5$ & $3500 \times 5$ \\
$2000 \times 6$ & $2250 \times 6$ & $2500 \times 6$ & $2750 \times 6$ & $3000 \times 6$ & $3250 \times 6$ & $3500 \times 6$ \\
$2000 \times 7$ & $2250 \times 7$ & $2500 \times 7$ & $2750 \times 7$ & $3000 \times 7$ & $3250 \times 7$ & $3500 \times 7$ \\
$2000 \times 8$ & $2250 \times 8$ & $2500 \times 8$ & $2750 \times 8$ & $3000 \times 8$ & $3250 \times 8$ & $3500 \times 8$ \\
$2000 \times 9$ & $2250 \times 9$ & $2500 \times 9$ & $2750 \times 9$ & $3000 \times 9$ & $3250 \times 9$ & $3500 \times 9$ \\
$2000 \times 10$ & $2250 \times 10$ & $2500 \times 10$ & $2750 \times 10$ & $3000 \times 10$ & $3250 \times 10$ & $3500 \times 10$ \\
\hline
\end{tabular}

To eliminate the noise fluctuation of the signal a Savitzky-Golay moving average filtering was applied to the raw signals [14]. Fig. 4 displays the film thickness versus time obtained for the three different mixtures of water and 1-butanol and the pure water, while keeping the volumetric flow rates of air and water constants at $(2250 \mathrm{l} / \mathrm{min})$ and $(7 \mathrm{l} / \mathrm{min})$ respectively. It is observed that the height of the disturbance waves diminishes continuously when increasing the 1-butanol concentration.
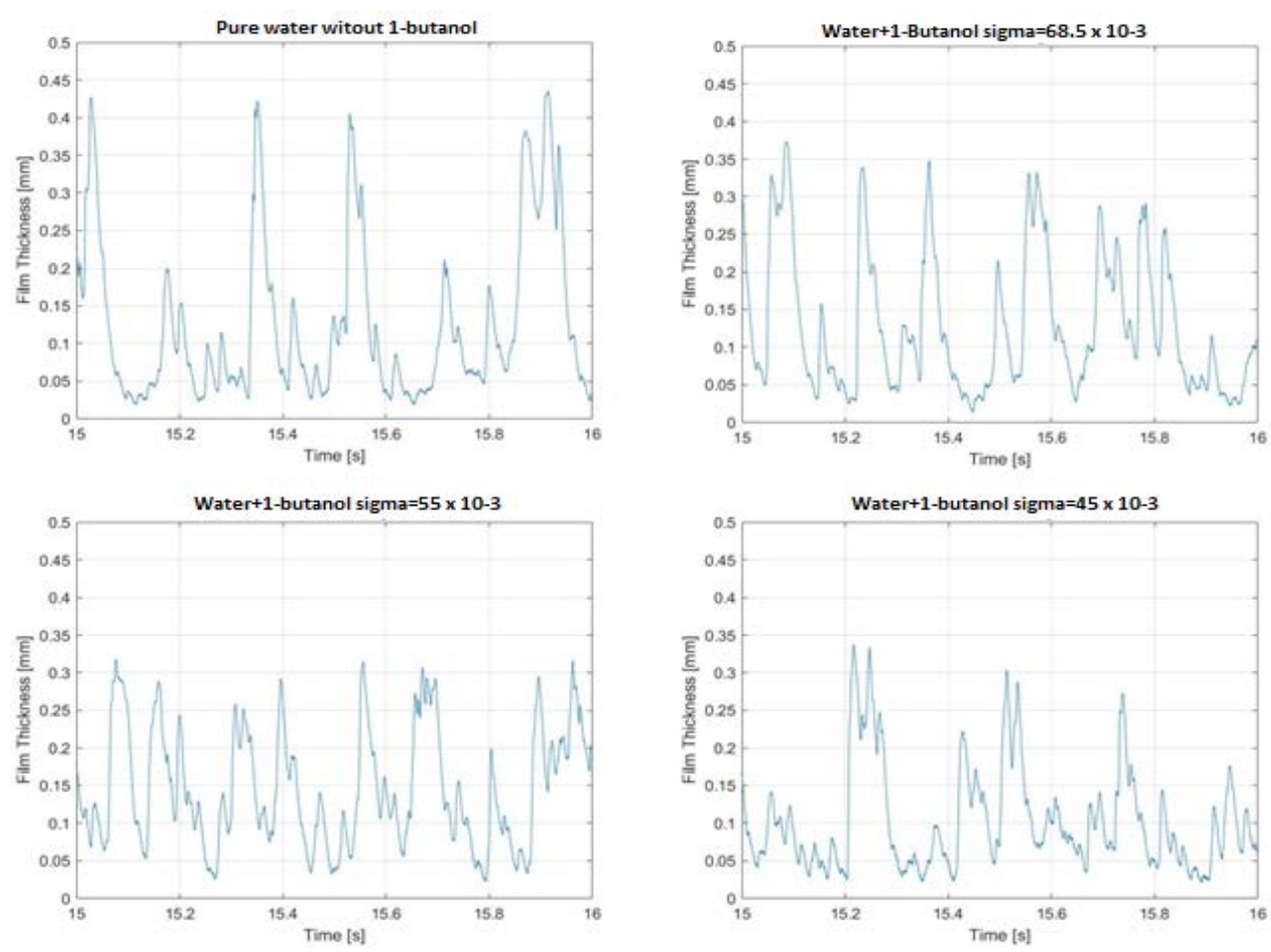

Figure 4: Film thickness evolution during one second for the different mixtures of water and 1-butanol keeping constant the volumetric flow rates of air $(2250 \mathrm{1} / \mathrm{min})$ and water $(7 \mathrm{l} / \mathrm{min})$. 
Aiming to estimate the error margin of the experimental measurements for the test series a set of repeated experiments has been made. A run test has been repeated ten times. In such a way that, assuming a normal probability distribution function, then the accidental error margin of a determined variable can be estimated through the following expression with a confidence level of $95 \%(\alpha=0.05)[15]$ :

$$
\varepsilon_{a c c}=t_{1-\alpha / 2}(f) \frac{s}{\sqrt{n}} .
$$

where $t_{1-\alpha / 2}(f)$ is the Student-t $1-\frac{\alpha}{2}$ quantile for $f=n-1$ degrees of freedom, which depends on the confidence level, and that for the usual $95 \%$ confidence level has a value of 2.26 , with 9 degrees of freedom. Notice that $\varepsilon_{a c c}$ is half the confidence interval for the mean given by: $\bar{\delta} \pm \mathrm{t}_{1-\alpha / 2}(f) \frac{S(\delta)}{\sqrt{n}}$, being $S(\delta)$ the square root of the variance. Table 3 displays the accidental errors computed with the data obtained repeating one of the experiments ten times.

The variables, which were obtained from the signal data were: the mean value of the amplitude of the disturbance waves, during the considered time interval for each run with given boundary conditions, denoted by $A_{D W}$, the mean value of the frequency of the disturbance waves denoted by $v_{D W}$, the base film thickness denoted by $\delta_{b}$, the mean film thickness $\bar{\delta}_{m}$, and the mean value of the film thickness at the disturbance waves denoted by $\bar{\delta}_{D W}$. Table 4 displays the results obtained for the runs with 1-butanol and $\sigma=55 \times 10^{-3} \mathrm{~N} / \mathrm{m}$, for $Q_{g}=2500 \mathrm{l} / \mathrm{m}$, and different values of $Q_{l}$, while Table 5 displays the same results obtained for water without adding 1-butanol, for the same cases.

From Tables 4 and 5 it is observed that when the surface tension increases the amplitude $A_{D W}$ of the disturbance waves increases, and also increases the frequency of the disturbance waves, this last fact means that we have a bigger number of disturbance waves per second. The base film thickness is not very much affected by diminishing the surface tension by adding 1-butanol. Also, we can study from these tables the effect of increasing the volumetric flow rate of air on the results. Because of the increase of the gas flow rate, it also increases the interfacial shear stress, which diminishes the base film thickness as observed comparing

Table 3: Accidental error from the repeatability analysis results for the main variables.

\begin{tabular}{|c|c|c|c|c|}
\hline & $\begin{array}{c}\varepsilon_{a c c}\left(\delta_{m}\right) \\
(\mu \mathrm{m})\end{array}$ & $\begin{array}{c}\varepsilon_{a c c}\left(\delta_{\mathrm{b}}\right) \\
(\mu \mathrm{m})\end{array}$ & $\begin{array}{c}\varepsilon_{a c c}\left(\mathrm{~A}_{\mathrm{DW}}\right) \\
(\mu \mathrm{m})\end{array}$ & $\begin{array}{c}\varepsilon_{a c c}\left(v_{\mathrm{DW}}\right) \\
(\mathrm{Hz})\end{array}$ \\
\hline$\varepsilon_{a c c}$ & 29.3 & 5.12 & 53.4 & 0.92 \\
\hline$\pm \varepsilon_{\text {rel,acc }} \%$ & \pm 6.2 & \pm 1.76 & \pm 7.9 & \pm 4.5 \\
\hline
\end{tabular}

Table 4: Experimental results for the water-1-butanol experiments with $\sigma=55 \times 10^{-3}$ $\mathrm{N} / \mathrm{m}$. All the results are expressed in $\mathrm{mm}$.

\begin{tabular}{|c|c|c|c|c|c|c|c|}
\hline$Q_{g} \times Q_{l}$ & $\bar{\delta}_{b}(\mathrm{~mm})$ & $\bar{\delta}_{D W}$ & $\bar{\delta}_{\text {ripples }}$ & $v_{D W}(\mathrm{~Hz})$ & $A_{\text {ripples }}$ & $A_{D W}$ & $\bar{\delta}_{m}$ \\
\hline $2500 \times 4$ & 0.12680 & 0.53267 & 0.14103 & 8.966 & 0.00712 & 0.4094 & 0.19057 \\
\hline $2500 \times 5$ & 0.13107 & 0.54601 & 0.14297 & 9.416 & 0.00595 & 0.4179 & 0.20957 \\
\hline $2500 \times 6$ & 0.13405 & 0.54833 & 0.14545 & 10.36 & 0.00570 & 0.4171 & 0.22747 \\
\hline $2500 \times 7$ & 0.13719 & 0.54720 & 0.14778 & 11.13 & 0.00530 & 0.4126 & 0.24316 \\
\hline $2500 \times 8$ & 0.13790 & 0.52920 & 0.14683 & 10.88 & 0.00447 & 0.3935 & 0.24623 \\
\hline $2500 \times 9$ & 0.14065 & 0.52677 & 0.14950 & 10.15 & 0.00443 & 0.3883 & 0.25594 \\
\hline $2500 \times 10$ & 0.14269 & 0.50716 & 0.15181 & 10.06 & 0.00456 & 0.3667 & 0.26088 \\
\hline
\end{tabular}


Table 5: Experimental results for the water experiments with $\sigma=72 \times 10^{-3} \mathrm{~N} / \mathrm{m}$. All the results are expressed in $\mathrm{mm}$.

\begin{tabular}{|c|c|c|c|c|c|c|c|}
\hline$Q_{g} \times Q_{l}$ & $\bar{\delta}_{b}(\mathrm{~mm})$ & $\bar{\delta}_{D W}$ & $\bar{\delta}_{\text {ripples }}$ & $v_{D W}(\mathrm{~Hz})$ & $A_{\text {ripples }}$ & $A_{D W}$ & $\bar{\delta}_{m}$ \\
\hline $2500 \times 4$ & 0.12904 & 0.61000 & 0.14447 & 10.39 & 0.00771 & 0.48480 & 0.20590 \\
\hline $2500 \times 5$ & 0.13365 & 0.62178 & 0.14750 & 11.22 & 0.00692 & 0.49158 & 0.22304 \\
\hline $2500 \times 6$ & 0.13814 & 0.62931 & 0.15170 & 12.41 & 0.00678 & 0.49456 & 0.24312 \\
\hline $2500 \times 7$ & 0.14285 & 0.63207 & 0.15614 & 13.52 & 0.00664 & 0.49253 & 0.25654 \\
\hline $2500 \times 8$ & 0.13423 & 0.64154 & 0.14630 & 13.93 & 0.00603 & 0.51032 & 0.26493 \\
\hline $2500 \times 9$ & 0.13559 & 0.64150 & 0.14692 & 14.19 & 0.00566 & 0.50874 & 0.26800 \\
\hline $2500 \times 10$ & 0.13483 & 0.64811 & 0.14874 & 14.74 & 0.00695 & 0.51676 & 0.27814 \\
\hline
\end{tabular}

Table 6: Experimental results for the water-1-butanol experiments with $Q_{g}=3000 \mathrm{l} / \mathrm{m}$ and $\sigma=55 \frac{\mathrm{N}}{\mathrm{m}}$, for a tube diameter $\mathrm{D}=44 \mathrm{~mm}$. All the results are expressed in $\mathrm{mm}$.

\begin{tabular}{|c|c|c|c|c|c|c|c|}
\hline$Q_{g} \times Q_{l}$ & $\bar{\delta}_{b}(\mathrm{~mm})$ & $\bar{\delta}_{D W}$ & $\bar{\delta}_{\text {ripples }}$ & $v_{D W}(\mathrm{~Hz})$ & $A_{\text {ripples }}$ & $A_{D W}$ & $\bar{\delta}_{m}$ \\
\hline $3000 \times 4$ & 0.09303 & 0.42337 & 0.10676 & 5.5 & 0.006867 & 0.33377 & 0.11697 \\
\hline $3000 \times 5$ & 0.10095 & 0.45039 & 0.11553 & 6.95 & 0.007286 & 0.35308 & 0.13530 \\
\hline $3000 \times 6$ & 0.10593 & 0.44924 & 0.12092 & 8.05 & 0.007496 & 0.34706 & 0.14798 \\
\hline $3000 \times 7$ & 0.10879 & 0.45189 & 0.12457 & 8.68 & 0.007890 & 0.34704 & 0.15622 \\
\hline $3000 \times 8$ & 0.11364 & 0.44024 & 0.12894 & 9.58 & 0.007649 & 0.33042 & 0.16645 \\
\hline $3000 \times 9$ & 0.11762 & 0.43667 & 0.13284 & 10.05 & 0.007610 & 0.32285 & 0.17728 \\
\hline $3000 \times 10$ & 0.12230 & 0.42726 & 0.13675 & 11.21 & 0.007223 & 0.30857 & 0.18825 \\
\hline
\end{tabular}

Tables 4 and 6 . Also, when increasing the gas superficial velocity diminishes the amplitude and mean thickness of the disturbance waves because the shear stress cut the peaks of the disturbance waves producing drops. As it is observed comparing Tables 4 and 6 .

Finally, a total of three correlations were obtained for the base film thickness, the total film thickness, and the amplitude of the disturbance waves in terms of the liquid Reynolds number $R e_{l i q}$, the gas Reynolds number $R e_{g}$, and the Kapitza number $K a$. The correlations obtained have the following form:

$$
\frac{\bar{\delta}_{m}}{D}=b_{1} R e_{\text {liq }}^{b_{2}} R e_{g}^{b_{3}} \mathrm{Ka}^{b_{4}},
$$

where the gas Reynolds number and the liquid film Reynolds number were obtained from the following expressions:

$$
R e_{g}=\frac{\rho_{g} J_{g} D}{\mu_{g}}, R e_{l}=\frac{\rho_{l} J_{l} D}{\mu_{l}}=\frac{4 \Gamma}{\mu_{l}},
$$

where $J_{g}$ and $J_{l}$, are the superficial velocities of the gas and the water-1-butanol mixture respectively and $\Gamma$ is the mass flow rate per unit of circumferential length. The coefficient of determination was 0.9883 and the root mean square error for $\bar{\delta}_{m}$ was 0.0224 . The values of the coefficients were, $b_{1}=0.805, b_{2}=0.3047, b_{3}=-0.9746$, and $b_{4}=0.411$.

Because of the frequency of the disturbance waves for pure water showed too much dispersion from one boundary condition to another one. Then, we repeated the experiments for all the boundary conditions three times at different days and we compute for each boundary condition the average value for the frequency, the results are displayed in the fifth column of Table 5 . 


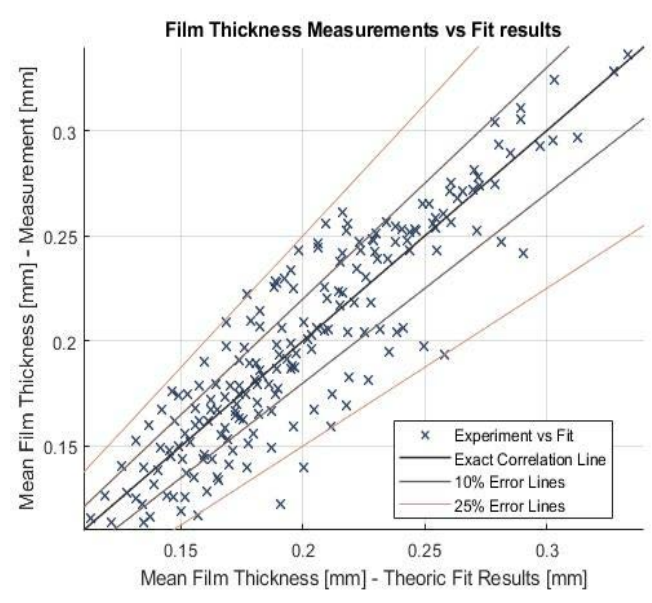

Figure 5: Experimental results versus correlation predictions for the average of the total film thickness.

\section{CONCLUSIONS}

The major conclusions of this paper are related to the evolution of the mean thickness $\bar{\delta}_{D W}$, and the amplitude $\mathrm{A}_{\mathrm{DW}}$ of the disturbance waves and the frequency $v_{D W}$ of these waves when varying the surface tension, and the liquid and gas superficial velocities while maintaining constant the tube diameter. It is observed that in general the mean thickness of the disturbance waves diminishes when the surface tension diminishes maintaining constant the gas and liquid superficial velocities, also the amplitude of the disturbance waves diminishes when reducing the values of the surface tension by adding 1-butanol to the water as observed comparing Tables 4 and 5. This reduction is about $20 \%$ in the amplitude and mean thickness of the disturbance waves, for the case of $Q_{g}=2500 \mathrm{l} / \mathrm{min}$ and different values of $Q_{l}$ ranging from $4 \mathrm{l} / \mathrm{min}$ to $10 \mathrm{l} / \mathrm{min}$ when changing from normal water to water with $\sigma=55.10^{-3} \mathrm{~N} / \mathrm{m}$. In addition, the frequency of the disturbance waves increases when we increase the surface tension from $5510^{-3}$ to $7210^{-3} \mathrm{~N} / \mathrm{m}$, as it is observed comparing the Tables 4 and 5 . This increment in the frequency of the waves is especially noteworthy when we also increase the superficial velocity of the liquid.

Another important issue is the influence of the gas superficial velocity on the amplitude of the disturbance waves (DW), this influence can be deduced comparing Tables 4 and 6 , for the same 1-butanol concentration. It is observed that $A_{D W}$ diminish when we increase the superficial velocity of the gas from $j_{g}=27.4 \mathrm{~m} / \mathrm{s}$ to $j_{g}=32.88 \mathrm{~m} / \mathrm{s}$. This reduction can be explained on account of the drag force produced by the interfacial shear stress on the crest of the disturbance waves that is able to cut the peak of the wave producing drops. This effect reduces the average amplitude of the DW, as deduced from Tables 4 and 6.

Finally, the factor that has the bigger influence on the total film average thickness is the gas superficial velocity, this influence can be deduced from the tables but also from the correlation obtained from all the experimental data. In this correlation appears $R e_{g}^{-0.9746}$, this means that because of $R e_{g}=\frac{\rho_{g} J_{g} D}{\mu_{g}}$, then the mean thickness of the film diminishes as $J_{g}^{-0.9746}$, i.e. with the superficial velocity of the gas. The explanation is that the shear stress produced by the gas flow at the interface reduces the film thickness. 


\section{ACKNOWLEDGEMENT}

The authors are indebted for the support of the Spain National Agency of Research to the project EXMOTRANSIN, ENE2016-79489-C2-1-P.

\section{REFERENCES}

[1] Collier, J.G., Convective Boiling and Condensation, 2nd ed., McGraw-Hill, 1981.

[2] Stephan, K., Heat Transfer in Condensation and Boiling, Springer Verlag, 1992.

[3] Berna, C., Escrivá, A., Muñoz-Cobo, J.L. \& Herranz, L.E., Review of droplet entrainment in annular flow: Interfacial waves and onset of entrainment. Progress in Nuclear Energy, 74, pp. 14-43, 2014.

[4] Berna, C., Escrivá, A., Muñoz-Cobo, J.L. \& Herranz, L.E., Review of droplet entrainment in annular flow: Characterization of the entrained droplets. Progress in Nuclear Energy, 79, pp. 64-86, 2015.

[5] Alekseenko, S., Antipin, V., Cherdantsev, A., Kharlamov, S. \& Markovich, D., Twowave structure of liquid film and wave interrelation in annular gas-liquid flow with and without entrainment. Physics of Fluids, 21(1), 061701, 2009.

[6] Belt, R.J., Van't Westende, J.M.C., Prasser, H.M. \& Portela, L.M., Time spatially resolved measurements of interfacial waves in vertical annular flow. International Journal of Multiphase Flow, 36, pp. 570-587, 2010.

[7] Azzopardi, B.J., Drops in annular two-phase flow. International Journal of Multiphase Flow, 23, pp. 1-53, 1997.

[8] Alekseenko, S., Antipin, V., Cherdantsev, A., Kharlamov, S. \& Markovich, D., Investigation of waves interaction in annular gas-liquid flow using high-speed fluorescent visualization technique. Microgravity Science Technology, 20(1), p. 271, 2008.

[9] Cuadros, J.L. et al., Experimental investigation of the gas-liquid interfacial waves in vertical upward concurrent annular flows. Nuclear Engineering and Design, in press, 2019.

[10] Muñoz-Cobo, J.L., Miquel, A., Berna, C. \& Escrivá, A., Spatial and time evolution of non-linear waves in falling liquid films by the harmonic expansion method with spatial integration. Proceedings of the International Conference on Heat Transfer, Fluid Mechanics and Thermodynamics HEFAT, 2016.

[11] Muñoz-Cobo, J.L, Chiva, S., Méndez, S., Monrós, G., Escrivá, A. \& Cuadros, J.L., Development of conductivity sensors for multi-phase flow local measurements at the Polytechnic University of Valencia (UPV) and University Jayme I of Castellon (UJI). Sensors, 17, pp. 1-35, 2017. DOI: 10.3390/s17051077.

[12] Wayne, C., The interfacial characteristics of falling film reactors. $\mathrm{PhD}$ thesis, University of Nottingham, Nottingham, UK, 2001.

[13] Bevington, P.R. \& Robinson, D.K., Data Reduction and Error Analysis in the Physical Sciences, 3rd ed., McGraw-Hill, 2003.

[14] Savitzky, A. \& Golay, M.J.E., Smoothing and differentiation of data by simplified least squares procedures. Analytical Chemistry, 36(8), pp. 1627-1639, 1964.

[15] Cramer, H., Elements of Probability Theory and Some of its Applications, 9th ed., Wiley, 1966. 